\title{
Qualidade fisiológica e sanitária de sementes de amendoim durante o processo de produção
}

\author{
Rafael Marani Barbosa(1), Bruno Guilherme Torres Licursi Vieira ${ }^{(2)}$, Cibele Chalita Martins ${ }^{(2)}$ \\ e Roberval Daiton Vieira ${ }^{(2)}$
}

\begin{abstract}
(1)Universidade Estadual de Santa Cruz, Departamento de Ciências Agrárias e Ambientais, Rodovia Jorge Amado, Km 16, CEP 45662-900 Ilhéus, BA, Brasil. E-mail: rmarani@gmail.com (2)Universidade Estadual Paulista, Departamento de Produção Vegetal, Campus de Jaboticabal, Via de Acesso Prof. Paulo Donato Castellane, s/no, CEP 14884-900 Jaboticabal, SP, Brasil. E-mail: vieirabgtl@gmail.com, cibele@fcav.unesp.br, rdvieira@fcav.unesp.br
\end{abstract}

Resumo - O objetivo deste trabalho foi avaliar o efeito das etapas do processo de produção sobre a qualidade fisiológica e sanitária de sementes de amendoim. Utilizou-se o delineamento experimental inteiramente casualizado com 12 tratamentos e quatro repetições. Os tratamentos consistiram de arranquio das plantas, recolha, transporte, secagem, armazenamento (dois, quatro e seis meses), além das seguintes etapas de beneficiamento: trilha mecânica, classificação por tamanho, separação por densidade e coloração, e tratamento químico. Avaliaram-se: o teor de água, a qualidade sanitária, a germinação e o vigor de sementes, após cada tratamento. Aspergillus spp. e Penicillium sp. foram encontrados nas sementes. No primeiro ano, após a trilha mecânica, as sementes apresentaram baixo desempenho. No processo de produção, o armazenamento promoveu a contaminação de $100 \%$ das sementes por Aspergillus spp. O tratamento químico foi eficiente na recuperação da qualidade sanitária da semente. As etapas de trilha mecânica e armazenamento reduzem a qualidade fisiológica das sementes de amendoim.

Termos para indexação: Arachis hypogaea, armazenamento, colheita, processamento, tratamento de sementes, vigor.

\section{Physiological and health quality of peanut seeds during the production process}

\begin{abstract}
The objective of this work was to evaluate the effect of production process stages on the physiological and health quality of peanut seeds. A completely randomized design with 12 treatments and four replicates was used. Treatments consisted of plant uprooting, plant gathering, transportation, drying, storage (two, four, and six months), and the following processing steps: mechanical threshing, classification by size, separation by density and color, and chemical treatment. Water content, health quality, germination, and vigor of seeds were evaluated after each treatment. Aspergillus spp. and Penicillium sp. were found in the seeds. In the first year, after mechanical threshing, seeds showed a reduced performance. In the production process, storage promoted the infection of $100 \%$ of the seeds by Aspergillus spp. The chemical treatment was effective in restoring seed health quality. Mechanical threshing steps and storage reduce the seed quality of peanut.
\end{abstract}

Index terms: Arachis hypogaea, storage, harvest, processing, seed treatment, vigor.

\section{Introdução}

A produção de sementes de amendoim (Arachis hypogaea L.) com alto potencial fisiológico requer técnica e manejo cuidadoso. No entanto, nem mesmo a produção mais tecnicizada consegue obter sementes viáveis e vigorosas. A produção com germinação suficiente, para garantir adequado estande de plantas, é um problema comum para os produtores de sementes de amendoim.

O amendoim, mesmo com ampla adaptabilidade, tem a produtividade muito influenciada pelas condições físicas do solo (Leonel et al., 2007) e por fatores ambientais, especialmente temperatura, disponibilidade de água e radiação (Haro et al., 2008; Silveira et al., 2013). Durante o período de colheita, esses fatores afetam diretamente a qualidade fisiológica das sementes. Baixos teores de água podem dificultar as operações de beneficiamento. Sementes muito secas estão mais sujeitas, à separação dos cotilédones e remoção do tegumento. A ausência do tegumento em sementes de espécies da família Fabaceae as configura como material inerte (Regras para análise de sementes, 2009), o que eleva o nível de perdas.

Nos sistemas de produção de amendoim, principalmente no Estado de São Paulo, a colheita é 
realizada mesmo quando a maior parte das sementes ainda não atingiu a maturidade fisiológica. Esta operação é acelerada quando as condições ambientais tornam-se propícias para a instalação da cultura da cana-de-açúcar, o que caracteriza o sistema de rotação de culturas em que se insere a produção de amendoim nesta região. Quando o ciclo da cultura do amendoim não é respeitado, são produzidas sementes com baixa qualidade fisiológica e sanitária. Das sementes de amendoim armazenadas no Estado de São Paulo, são comercializados lotes com germinação inferior ao padrão estabelecido (70\%). Esse baixo desempenho, muitas vezes, é atribuído ao ataque de insetos e a elevados índices de infecção causada por fungos dos gêneros Aspergillus, Fusarium, Penicillium e Rhizopus (Santos et al., 2013b).

Além da baixa qualidade sanitária, outros fatores podem afetar a qualidade dos lotes, como a falta de uniformidade na maturação das sementes (Carley et al., 2008; Branch et al., 2010), a ocorrência de chuvas durante a "cura" (Santos et al., 2013a), os danos oriundos de ataque de insetos (Santos et al., 2013b), os problemas técnicos na colheita, secagem e beneficiamento (Lopes et al., 2011) e a falta de monitoramento da qualidade durante as etapas de produção (Morton et al., 2008). A identificação de falhas nestas etapas, que podem causar redução do desempenho das sementes, é de primordial importância para o sucesso da produção de sementes.

Em razão da maturidade relativamente tardia que as cultivares Runner apresentam (Balota \& Phipps, 2013), muitas vezes o calor e chuvas intensas no período de colheita não permitem as operações mecanizadas e a secagem natural ou cura, o que interfere na produtividade e qualidade de sementes (Haro et al., 2008). Além disso, o amendoim apresenta desenvolvimento indeterminado (Branch et al., 2010), e mesmo quando a colheita ocorre em momento ótimo, são colhidas vagens em diferentes estádios de maturação (Carley et al., 2008; Dorner, 2008).

À medida que as sementes são beneficiadas, estão sujeitas a danos mecânicos imediatos e latentes. Embora, os danos às sementes durante a colheita, secagem e armazenamento sejam reduzidos, pois estão protegidas pela vagem, a trilha mecânica, a classificação por tamanho e a separação por densidade podem causar a redução da germinação e vigor, além de permitir a infestação por patógenos (Sader et al.,
1991; Fessel \& Barreto, 2000), pois as sementes de amendoim possuem tegumento delgado e delicado, o que as torna sensíveis ao dano mecânico, quando o beneficiamento é inadequado.

Assim, o processamento pode não aprimorar a qualidade fisiológica e sanitária de sementes de amendoim, conforme constatado para 'Tatu Vermelho' (Fessel \& Barreto, 2000) e 'Runner IAC 503' e 'Runner IAC 886' (Santos et al., 2013b). Porém, sabe-se que as operações de beneficiamento são imprescindíveis, para que se obtenham sementes de elevada qualidade, como ocorre no beneficiamento de sementes de arroz (Pereira et al., 2012), milho (Ferreira \& Sá, 2010) e soja (Lopes et al., 2011).

$\mathrm{O}$ efeito das etapas de beneficiamento sobre as sementes de amendoim não está totalmente esclarecido, pois, muitos fatores podem afetar a qualidade delas (Morton et al., 2008) e, em alguns casos, podemse beneficiar sementes que já vieram do campo com baixa qualidade fisiológica e sanitária. Assim, são necessários estudos quanto à produção de sementes de amendoim, que possam contribuir para o aumento da eficiência dos processos da colheita ao beneficiamento.

O objetivo deste trabalho foi avaliar o efeito das etapas do processo de produção sobre a qualidade fisiológica e sanitária de sementes de amendoim.

\section{Material e Métodos}

Para o experimento, utilizaram-se sementes de amendoim 'Runner IAC 886' (grupo Virgínia), produzidas em dois anos agrícolas, nos campos sob responsabilidade da Cooperativa dos Plantadores de Cana da Zona de Guariba (Coplana). No ano agrícola $2011 / 2012$, o campo localizou-se a $21^{\circ} 14^{\prime} 15^{\prime \prime S}$ e $48^{\circ} 21^{\prime} 09^{\prime \prime} \mathrm{W}$, a $660 \mathrm{~m}$ de altitude e, em 2012/2013, a $21^{\circ} 06^{\prime} 38^{\prime \prime S}$ e $48^{\circ} 18^{\prime} 45^{\prime \prime} \mathrm{W}$, a $599 \mathrm{~m}$ de altitude, dentro dos limites do Município de Jaboticabal, SP.

Durante o período de cultura, 2011/2012 e 2012/2013, os dados climatológicos, temperatura média e precipitação, foram registrados pela Estação Agroclimatológica da Faculdade de Ciências Agrárias e Veterinárias, Unesp, Campus de Jaboticabal (Figura 1).

As sementes de amendoim foram amostradas no campo e na Unidade de Beneficiamento de Sementes (UBS). Para cada etapa do processo de produção colheita, armazenamento, beneficiamento por trilha mecânica, classificação por tamanho, separação 
por densidade, coloração e tratamento químico obtiveram-se quatro amostras simples que, após homogeneização, formaram a amostra composta que, posteriormente, foi levada ao Laboratório de Análises de Sementes, do Departamento de Produção Vegetal, Unesp. As sementes provenientes das etapas de colheita até o fim do armazenamento foram trilhadas manualmente; após cada etapa do beneficiamento realizada na UBS, obtiveram-se sementes já descascadas para as análises.

No primeiro ano agrícola, o arranquio das plantas de amendoim ocorreu no dia 07 de março de 2012 e, no segundo ano, em 21 de fevereiro de 2013. Em ambos os anos, a cultura apresentou ciclo de 130 dias. A recolha do amendoim foi realizada três dias após o arranquio, em 2011/2012, e após seis dias, em 2012/2013, o que correspondeu ao período de secagem natural ou cura das vagens que é realizado no campo.

Utilizou-se o delineamento experimental inteiramente casualizado, com 12 tratamentos e quatro repetições. Os tratamentos constituíram-se das etapas de produção às quais as sementes foram submetidas e posteriormente amostradas: T1, arranquio mecanizado das plantas e cura natural das vagens; T2, recolha mecanizada, amostragem realizada junto ao tanque graneleiro da recolhedora, com as vagens já desprendidas das plantas no campo; T3, transporte do campo à UBS, com as sementes ainda em vagens, antes da secagem; T4, secagem, em que as vagens passaram por processos de pré-limpeza, secagem, e limpeza, antes do ensacamento; T5, dois meses de armazenamento das vagens em sacos de polietileno trançado de $200 \mathrm{~kg}$, em condição de ambiente de armazém $\left(25^{\circ} \mathrm{C}\right.$ e $\left.60 \% \mathrm{UR}_{\mathrm{ar}}\right)$; $\mathrm{T} 6$, quatro meses de armazenamento $\left(25^{\circ} \mathrm{C}\right.$ e $60 \%$ $\left.\mathrm{UR}_{\mathrm{ar}}\right) ; \mathrm{T} 7$, seis meses de armazenamento $\left(25^{\circ} \mathrm{C}\right.$ e $60 \%$ $\mathrm{UR}_{\mathrm{ar}}$ ); T8, beneficiamento - por trilha mecânica; T9, classificação, por tamanho, das sementes coletadas da peneira 23; T10, separação por densidade das sementes pela mesa densimétrica; T11, seleção por coloração, por meio de seletora eletrônica; T12, tratamento químico comercial de sementes.

Depois de colhidas, as sementes são mantidas dentro das próprias vagens durante as etapas iniciais até o fim do armazenamento (T1 a T7), e após esse período é realizada a trilha mecânica. Assim, as sementes provenientes dos tratamentos $\mathrm{T} 1$ a $\mathrm{T} 7$ foram manualmente trilhadas, limpas e classificadas por tamanho (peneira de crivo redondo de $23 \mathrm{~mm}$ ). As amostras de cada tratamento foram devidamente identificadas e mantidas em câmara seca $\left(25^{\circ} \mathrm{C}\right.$ e $40 \%$ de $U_{\mathrm{ar}}$ ), sem tratamento químico com fungicidas ou inseticidas, exceto aquelas provenientes do T12, até o momento da realização das avaliações.

O tratamento químico comercial (T12) consistiu da aplicação de fungicida, inseticida, micronutrientes e polímero. Utilizaram-se o fungicida

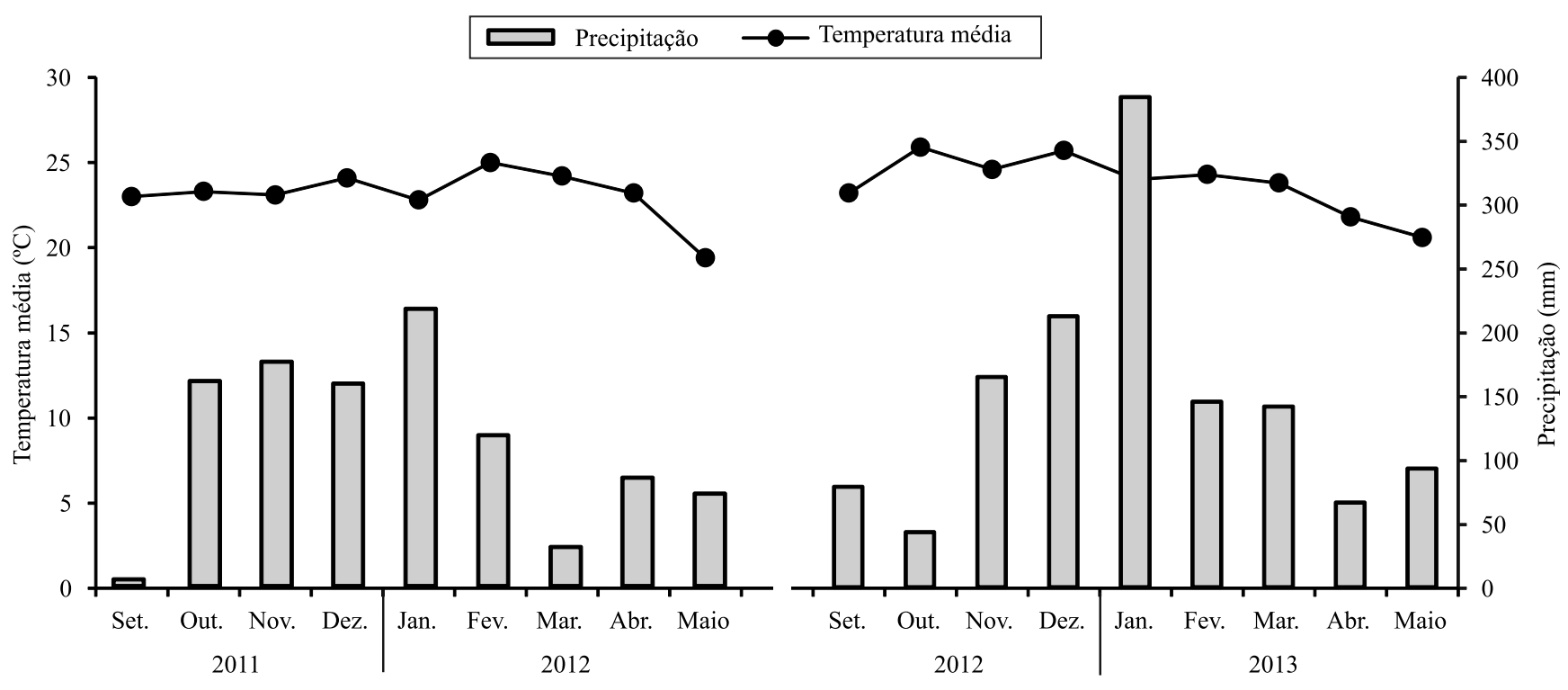

Figura 1. Climograma para o período de implantação e condução da cultura: precipitação e temperatura média mensais, para os anos agrícolas de 2011/2012 e 2012/2013. Fonte: Estação Agroclimatológica, Fcav, Unesp, Campus de Jaboticabal. 
fludioxonil+metalaxyl, à dose de $200 \mathrm{~mL}$ do produto comercial (p.c.), em $100 \mathrm{~kg}$ de sementes, e o inseticida tiametoxam, a $150 \mathrm{~mL}$ do p.c. em $100 \mathrm{~kg}$ de sementes; para o fornecimento dos micronutrientes, utilizou-se produto com concentração de $1,5 \%$ de cobalto e $14 \%$ de molibdênio, à dose de $200 \mathrm{~mL}$ do p.c. em $100 \mathrm{~kg}$ de sementes; utilizou-se ainda o polímero Laborsan (Laborsan, Diadema, SP,), destinado ao revestimento de sementes, à dose de $200 \mathrm{~mL}$ em $100 \mathrm{~kg}$ de sementes.

Todos os tratamentos foram submetidos à determinação do teor de água e avaliações das qualidades sanitária e fisiológica.

O teor de água foi determinado com duas repetições de 25 sementes, em estufa a $105 \pm 3^{\circ} \mathrm{C}$, durante 24 horas (Regras para análise de sementes, 2009), e os resultados foram expressos em percentagem (base úmida). Para a avaliação da sanidade, quatro repetições de 50 sementes foram incubadas em placas de Petri (9 $\mathrm{cm}$ de diâmetro), que continha três folhas de papel-filtro umedecidas com água destilada; utilizaram-se 20 placas por tratamento e 10 sementes em cada placa. As placas foram mantidas em ambiente controlado, a $20 \pm 2^{\circ} \mathrm{C}$, por sete dias, com fotoperíodo de 12 horas. A avaliação foi realizada em cada semente, sob microscópio estereoscópico e microscópio óptico. A identificação dos fungos foi realizada por meio de características morfológicas de seu crescimento, e os resultados foram expressos em percentagem de sementes infectadas (Limonard, 1966).

Para avaliar a capacidade de germinação, utilizaram-se 8 repetições de 25 sementes de cada tratamento. As sementes foram tratadas quimicamente - com fungicida thiram (500 $\mathrm{g} \mathrm{L}^{-1}$ i.a.) à dose de $300 \mathrm{~mL}$ de p.c. para cada $100 \mathrm{~kg}$ de sementes (Regras para análise de sementes, 2009; Barbosa et al., 2013) - e distribuídas em rolos de papel de germinação, umedecidos com água deionizada equivalente a três vezes a massa do substrato seco e colocados em câmara de germinação a $25^{\circ} \mathrm{C}$. As avaliações foram realizadas no quinto dia, correspondente à avaliação de primeira contagem de germinação, e no décimo dia após a semeadura, tendo-se computado a percentagem de plântulas normais (Regras para análise de sementes, 2009).

A velocidade de emergência de plântulas (IVE) foi obtida a partir do teste de germinação em areia, por meio de contagens diárias de plântulas emersas, tendose considerado aquelas cujos cotilédones atingiram o nível do substrato. Posteriormente, calculou-se o IVE (Maguire, 1962).

$\mathrm{Na}$ avaliação da condutividade elétrica, quatro repetições de 50 sementes de cada tratamento foram pesadas e colocadas para embeber $75 \mathrm{~mL}$ de água deionizada a $25^{\circ} \mathrm{C}$, por 24 horas, em copos de plástico com capacidade de $200 \mathrm{~mL}$. Após esse período, a condutividade elétrica da solução foi medida, e os resultados, expressos em $\mu \mathrm{S} \mathrm{cm} \mathrm{cm}^{-1} \mathrm{~g}^{-1}$ (Marcos-Filho \&Vieira, 2009; Barbosa et al., 2012).

Realizou-se o teste tetrazólio com quatro repetições de 25 sementes de cada tratamento, pré-condicionadas por 16 horas a $25^{\circ} \mathrm{C}$ por imersão em água. Posteriormente, os cotilédones foram separados com auxílio de lâmina e imersos em solução de 2,3,5-trifenil cloreto de tetrazólio a $0,075 \%$, por 2 horas, a $40^{\circ} \mathrm{C}$, para coloração. Os resultados foram expressos em porcentagem de sementes viáveis (Santos et al., 2012).

Para a avaliação da emergência das plantas em campo, quatro repetições de 50 sementes tratadas quimicamente, conforme descrito para a germinação, foram semeadas em sulcos de $2 \mathrm{~m}$ de comprimento e 3-4 cm de profundidade. Os sulcos foram espaçados em $0,4 \mathrm{~m}$ e avaliados depois de 15 dias da semeadura, tendo-se computado as plântulas cujas folhas originárias do embrião (folhas simples) apresentavam-se desenvolvidas, em que as margens não se tocavam mais.

Os dados foram testados quanto à normalidade (teste de Anderson-Darling) e homogeneidade das variâncias e, por atenderem às exigências da análise de variância, não foram transformados. Posteriormente, foram submetidos à análise de variância, e as médias foram comparadas pelo teste de Scott-Knott, a 5\% de probabilidade (Pimentel-Gomes, 2009).

\section{Resultados e Discussão}

Em março de 2012, houve baixa pluviosidade e temperaturas elevadas que, em conjunto, favoreceram o processo de cura do amendoim (Figura 1). No ano agrícola 2012/2013, a maior pluviosidade durante o período de colheita prolongou o período de cura em relação ao ano anterior. Além disso, temperatura e umidade relativa do ar elevadas ocasionaram o aumento do período de molhamento da cultura, o que tornou o ambiente favorável ao desenvolvimento de 
microrganismos, ao aumento da população de fungos e à incidência de doenças.

O teor de água das sementes provenientes das diferentes etapas do processo de produção variou de 4,2 a $6,2 \%$ e 5,4 a $6,4 \%$, para as amostras provenientes de 2011/2012 e 2012/13, respectivamente (Tabela 1). Estes valores relativamente baixos de teor de água são comumente encontrados em sementes de amendoim, em razão do alto teor de óleo da semente (Nautiyal, 2009; Wang et al., 2012) e do ambiente com baixa umidade relativa do ar, durante os processos de produção de sementes (Carvalho \& Nakagawa, 2012).

A uniformidade do teor de água, entre os diferentes tratamentos, proporciona segurança na avaliação da qualidade das sementes, o que é imprescindível para a obtenção de resultados consistentes (Vieira et al., 2002). Durante a colheita e o arranquio das plantas e posterior cura das vagens (T1), houve baixa ocorrência de fungos e, ao final do armazenamento (T7), houve a plena colonização por fungos do gênero Aspergillus e menor presença do gênero Penicillium (Tabela 2). A baixa ocorrência de Penicillium sp. pode ser atribuída à competição deste com Aspergillus spp. (Vechiato et al., 1994).

Sementes infectadas por patógenos diferem, quanto à massa específica, das sementes sadias, as quais podem serseparadas namesa densimétrica (Gadotti etal.,2011). Porém, para sementes de amendoim, a separação por densidade promovida pela mesa densimétrica não foi capaz de selecionar lotes com boa qualidade sanitária,

Tabela 1. Teor de água de sementes de amendoim 'Runner IAC 886 ', provenientes de diferentes etapas (tratamentos) do processo de produção nos anos agrícolas 2011/2012 e $2012 / 2013$.

\begin{tabular}{lcc}
\hline Tratamento & 2011/2012 & 2012/2013 \\
& --------- \\
\hline T1, arranquio & 6,1 & 5,9 \\
T2, recolha & 6,2 & 5,8 \\
T3, transporte & 6,2 & 6,0 \\
T4, secagem & 6,2 & 6,2 \\
T5, armazenamento por dois meses & 6,2 & 6,4 \\
T6, armazenamento por quatro meses & 4,4 & 6,2 \\
T7, armazenamento por seis meses & 4,2 & 5,9 \\
T8, trilha mecânica & 5,6 & 5,7 \\
T9, classificação por tamanho & 5,6 & 5,5 \\
T10, separação pela mesa densimétrica & 5,4 & 5,8 \\
T11, seleção por coloração & 5,5 & 5,9 \\
T12, tratamento químico comercial & 5,0 & 6,2 \\
\hline
\end{tabular}

pois não alterou os níveis de infecção (Tabela 2). Os patógenos encontrados são considerados fungos de armazenamento, e a contaminação é geralmente decorrente do contato com o solo, no momento da colheita (Atayde et al., 2012), e de condições de armazenamento que favorecem o desenvolvimento dos fungos. Ao final do armazenamento, todas as sementes estavam contaminadas por Aspergillus spp. Marchi et al. (2011), que trabalharam com sementes de amendoim com 4\% de contaminação por Aspergillus spp, detectaram, após seis meses do armazenamento, que a ocorrência do patógeno atingiu 57\%.

O tratamento de sementes de amendoim é eficiente para controlar fungos de armazenamento. Porém, Marchi et al. (2011) observaram incrementos da presença de Aspergillus spp. e redução da qualidade fisiológica a partir 90 dias após o tratamento químico. Assim, o tratamento de sementes de amendoim, antes da semeadura, é de fundamental importância para a comercialização e o estabelecimento adequado do estande (Bittencourt et al., 2007; Barbosa et al., 2013; Santos et al., 2013b).

As sementes provenientes das etapas de arranquio até os quatro meses de armazenamento (T1 a T6) apresentaram elevados níveis de qualidade fisiológica

Tabela 2. Incidência de fungos associados a sementes de amendoim 'Runner IAC 886', provenientes de diferentes etapas (tratamentos) do processo de produção nos anos agrícolas 2011/2012 e 2012/2013.

\begin{tabular}{|c|c|c|c|c|}
\hline \multirow{2}{*}{$\begin{array}{l}\text { Trata- } \\
\text { mento }^{(1)}\end{array}$} & \multicolumn{2}{|c|}{$2011 / 2012$} & \multicolumn{2}{|c|}{$2012 / 2013$} \\
\hline & \multicolumn{4}{|c|}{ 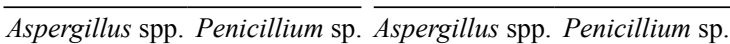 } \\
\hline & 20 & 2 & 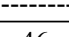 & $a^{2}$ \\
\hline $\mathrm{T} 1$ & 38 & 31 & 46 & 26 \\
\hline $\mathrm{T} 2$ & 94 & 94 & 49 & 62 \\
\hline T3 & 90 & 97 & 85 & 97 \\
\hline $\mathrm{T} 4$ & 93 & 99 & 94 & 92 \\
\hline T5 & 100 & 100 & 100 & 95 \\
\hline T6 & 100 & 2 & 100 & 98 \\
\hline $\mathrm{T} 7$ & 100 & 2 & 100 & 11 \\
\hline T8 & 100 & 2 & 100 & 12 \\
\hline T9 & 100 & 8 & 100 & 17 \\
\hline $\mathrm{T} 10$ & 100 & 14 & 100 & 8 \\
\hline $\mathrm{T} 11$ & 100 & 15 & 100 & 11 \\
\hline $\mathrm{T} 12$ & 25 & 8 & 16 & 9 \\
\hline
\end{tabular}

${ }^{(1)} \mathrm{T} 1$, arranquio; T2, recolha; T3, transporte; T4, secagem; T5, armazenamento por dois meses; T6, armazenamento por quatro meses; T7, armazenamento por seis meses; T8, trilha mecânica; T9, classificação por tamanho; T10, separação pela mesa densimétrica; T11, seleção por coloração; T12, tratamento químico comercial. 
somente quanto ao primeiro ano do estudo (Tabela 3 ). No ano agrícola 2011/2012, as sementes oriundas destas etapas apresentaram germinação com valores acima do padrão estabelecido para comercialização. Pelo fato de estas etapas estarem naturalmente próximas do ponto de maturidade fisiológica, as sementes apresentam maior qualidade fisiológica.

As sementes provenientes das etapas de arranquio apresentaram elevados níveis de vigor até aos quatro meses de armazenamento (T1 a T6), (Tabela 3), o que é indicativo de que apresentavam potencial para a rápida germinação e maior resistência ao armazenamento, além de membranas celulares bem estruturadas (Vieira et al., 2002).

Com o fim do armazenamento e início do beneficiamento (T7 em diante) das sementes do ano agrícola 2011/2012, houve decréscimo da qualidade fisiológica com o acúmulo das etapas (Tabela 3). As sementes apresentaram baixa germinação e vigor, o que foi verificado em todas as avaliações.

Tabela 3. Germinação $(G)$, primeira contagem de germinação (PC), índice de velocidade de emergência (IVE), condutividade elétrica $(\mathrm{CE})$, emergência de plântulas em campo (EPC) e viabilidade pelo teste de tetrazólio (TZ) de sementes de amendoim 'Runner IAC 886', provenientes de diferentes etapas (tratamentos) do processo de produção do ano agrícola $2011 / 2012^{(1)}$.

\begin{tabular}{lcccccc}
\hline Tratamento $^{(2)}$ & $\begin{array}{c}\mathrm{G} \\
(\%)\end{array}$ & $\begin{array}{c}\text { PC } \\
(\%)\end{array}$ & IVE & $\begin{array}{c}\mathrm{CE} \\
\left(\mu \mathrm{Scm}^{-1} \mathrm{~g}^{-1}\right)\end{array}$ & $\begin{array}{c}\mathrm{EPC} \\
(\%)\end{array}$ & $\begin{array}{c}\mathrm{TZ} \\
(\%)\end{array}$ \\
\hline T1 & $86 \mathrm{a}$ & $84 \mathrm{a}$ & $8,4 \mathrm{a}$ & $5,6 \mathrm{a}$ & $63 \mathrm{a}$ & $82 \mathrm{a}$ \\
T2 & $92 \mathrm{a}$ & $90 \mathrm{a}$ & $9,1 \mathrm{a}$ & $10,5 \mathrm{a}$ & $44 \mathrm{c}$ & $76 \mathrm{a}$ \\
T3 & $93 \mathrm{a}$ & $90 \mathrm{a}$ & $9,1 \mathrm{a}$ & $11,8 \mathrm{a}$ & $52 \mathrm{~b}$ & $69 \mathrm{~b}$ \\
T4 & $88 \mathrm{a}$ & $84 \mathrm{a}$ & $8,6 \mathrm{a}$ & $12,1 \mathrm{a}$ & $55 \mathrm{~b}$ & $63 \mathrm{~b}$ \\
T5 & $84 \mathrm{a}$ & $75 \mathrm{a}$ & $7,9 \mathrm{a}$ & $13,6 \mathrm{a}$ & $51 \mathrm{~b}$ & $64 \mathrm{~b}$ \\
T6 & $92 \mathrm{a}$ & $88 \mathrm{a}$ & $8,9 \mathrm{a}$ & $18,9 \mathrm{~b}$ & $69 \mathrm{a}$ & $79 \mathrm{a}$ \\
T7 & $53 \mathrm{~b}$ & $52 \mathrm{~b}$ & $5,2 \mathrm{~b}$ & $48,5 \mathrm{~d}$ & $34 \mathrm{~d}$ & $46 \mathrm{c}$ \\
T8 & $32 \mathrm{c}$ & $29 \mathrm{c}$ & $3,0 \mathrm{c}$ & $40,8 \mathrm{c}$ & $45 \mathrm{c}$ & $42 \mathrm{c}$ \\
T9 & $57 \mathrm{~b}$ & $55 \mathrm{~b}$ & $5,6 \mathrm{~b}$ & $55,5 \mathrm{~d}$ & $39 \mathrm{c}$ & $33 \mathrm{c}$ \\
T10 & $48 \mathrm{~b}$ & $44 \mathrm{~b}$ & $4,6 \mathrm{~b}$ & $49,6 \mathrm{e}$ & $30 \mathrm{~d}$ & $32 \mathrm{c}$ \\
T11 & $46 \mathrm{~b}$ & $44 \mathrm{~b}$ & $4,5 \mathrm{~b}$ & $57,5 \mathrm{~d}$ & $33 \mathrm{~d}$ & $45 \mathrm{c}$ \\
T12 & $28 \mathrm{c}$ & $23 \mathrm{c}$ & $2,5 \mathrm{c}$ & $68,1 \mathrm{f}$ & $27 \mathrm{~d}$ & $40 \mathrm{c}$ \\
\hline Teste F & $31,9^{* *}$ & $38,6^{* *}$ & $36,3^{* *}$ & $120,5 * *$ & $13,8^{* *}$ & $19,2 * *$ \\
CV $(\%)$ & 13,3 & 12,8 & 12,8 & 12,6 & 10,1 & 14,9 \\
\hline
\end{tabular}

(1)Médias seguidas de letras iguais, nas colunas, não diferem entre si, pelo teste de Scott-Knott, a 5\% de probabilidade. ${ }^{(2)} \mathrm{T} 1$, arranquio; T2, recolha; T3, transporte; T4, secagem T5, armazenamento por dois meses; T6, armazenamento por quatro meses; T7, armazenamento por seis meses; T8, trilha mecânica; T9, classificação por tamanho; T10, separação pela mesa densimétrica; T11, seleção por coloração; T12, tratamento químico comercial. **Significativo a $1 \%$ de probabilidade, pelo teste $\mathrm{F}$.
No primeiro ano, durante o beneficiamento, a qualidade fisiológica das sementes apresentou redução dos valores, principalmente após a operação de trilha mecânica (T8). O atrito do cilindro trilhador, empregado para extrair as sementes das vagens, ocasionou problemas de qualidade e inatividade dos tecidos do embrião, principalmente do eixo embrionário verificado pela sua não coloração pelo tetrazólio, além de reduzir os valores de germinação (Tabela 3). Ainda neste mesmo ano, da classificação até o tratamento químico comercial, não houve manutenção da qualidade fisiológica, avaliada pelos testes de primeira contagem de germinação, IVE, condutividade elétrica e emergência de plântulas em campo. De acordo com os testes, as etapas finais do processo de beneficiamento de sementes, a partir da trilha mecânica, não contribuíram para a qualidade do lote formado.

No primeiro ano avaliado, das etapas de trilha mecânica até o tratamento químico (T8 a T12), as sementes apresentaram baixo desempenho nas avaliações de germinação e emergência de plântulas em campo (Tabela 3). Verificou-se, pelo teste de tetrazólio, que as sementes não germinaram, por estarem mortas ou com graves lesões nos tecidos do eixo embrionário, o que foi confirmado pelos resultados da avaliação da condutividade elétrica da solução de embebição. Os elevados valores são indicativos de que ocorreu maior liberação de lixiviados para a solução, em decorrência de problemas de integridade das membranas celulares, nos diversos tecidos que compõem a semente (Barbosa et al., 2012). A obtenção de sementes com baixa qualidade fisiológica, ao final das etapas, não se repetiu no ano seguinte (Tabela 4), em que, ao final do processo, as sementes produzidas apresentaram maiores níveis de germinação e vigor.

No ano agrícola 2012/2013, as sementes provenientes das etapas de colheita apresentaram desempenho inferior (Tabela 4) até aos seis meses de armazenamento (T1 a T7), conforme o teste de germinação e vigor. Nestas etapas, a germinação apresentou redução de $64 \%$ no arranquio para $50 \%$ no final do armazenamento. Deve-se ressaltar que o material que veio do campo de produção era heterogêneo, composto por sementes de intermediária à alta qualidade, sementes maduras e imaturas, atacadas por insetos e microrganismos e até mesmo sementes dormentes. 
Durante o processo de cura, no ano agrícola de 2012/2013, em consequência da maior ocorrência de chuvas, as sementes, após a maturidade fisiológica, passaram por ciclos de umedecimento e secagem, o que acelerou o processo de deterioração no campo. Logo, verificaram-se baixos valores para a germinação e vigor das sementes provenientes das etapas de arranquio até o fim do armazenamento (T1 a T7).

Com o fim do armazenamento e início do beneficiamento, as sementes com qualidade superior foram selecionadas durante as etapas. Com o decorrer das etapas, após a trilha mecânica (T8), houve incremento dos valores de germinação, primeira contagem de germinação, IVE, condutividade elétrica e emergência de plântulas no campo (Tabela 4). No final do processo, no ano 2011/2012, as amostras apresentaram $28 \%$ de germinação, enquanto em $2012 / 2013$ esta variável atingiu $85 \%$.

No segundo ano, o armazenamento ocasionou a redução da qualidade fisiológica enquanto $o$

Tabela 4. Germinação $(\mathrm{G})$, primeira contagem de germinação (PC), índice de velocidade de emergência (IVE), condutividade elétrica (CE), emergência de plântulas em campo (EPC) e viabilidade pelo teste de tetrazólio (TZ) de sementes de amendoim 'Runner IAC 886', provenientes de diferentes etapas (tratamentos) do processo de produção no ano agrícola $2012 / 2013^{(1)}$.

\begin{tabular}{lcccccc}
\hline Tratamento $^{(2)}$ & $\begin{array}{c}\mathrm{G} \\
(\%)\end{array}$ & $\begin{array}{c}\text { PC } \\
(\%)\end{array}$ & IVE & $\begin{array}{c}\mathrm{CE} \\
\left(\mu \mathrm{Scm}^{-1} \mathrm{~g}^{-1}\right)\end{array}$ & $\begin{array}{r}\mathrm{EPC} \\
(\%)\end{array}$ & $\begin{array}{c}\mathrm{TZ} \\
(\%)\end{array}$ \\
\hline T1 & $64 \mathrm{c}$ & $52 \mathrm{~d}$ & $6,5 \mathrm{~b}$ & $23,2 \mathrm{a}$ & $61 \mathrm{c}$ & $70 \mathrm{~b}$ \\
T2 & $59 \mathrm{~d}$ & $38 \mathrm{f}$ & $4,8 \mathrm{c}$ & $27,4 \mathrm{a}$ & $38 \mathrm{~d}$ & $59 \mathrm{~b}$ \\
T3 & $55 \mathrm{e}$ & $41 \mathrm{f}$ & $4,9 \mathrm{c}$ & $26,8 \mathrm{a}$ & $43 \mathrm{~d}$ & $42 \mathrm{c}$ \\
T4 & $52 \mathrm{e}$ & $43 \mathrm{e}$ & $4,8 \mathrm{c}$ & $35,6 \mathrm{~b}$ & $23 \mathrm{e}$ & $71 \mathrm{~b}$ \\
T5 & $47 \mathrm{f}$ & $37 \mathrm{f}$ & $4,2 \mathrm{c}$ & $39,0 \mathrm{~b}$ & $34 \mathrm{~d}$ & $59 \mathrm{~b}$ \\
T6 & $48 \mathrm{f}$ & $36 \mathrm{f}$ & $4,2 \mathrm{c}$ & $31,4 \mathrm{~b}$ & $34 \mathrm{~d}$ & $52 \mathrm{c}$ \\
T7 & $50 \mathrm{f}$ & $44 \mathrm{e}$ & $4,2 \mathrm{c}$ & $34,2 \mathrm{~b}$ & $53 \mathrm{c}$ & $67 \mathrm{~b}$ \\
T8 & $65 \mathrm{c}$ & $61 \mathrm{c}$ & $5,9 \mathrm{c}$ & $32,3 \mathrm{~b}$ & $78 \mathrm{~b}$ & $79 \mathrm{a}$ \\
T9 & $77 \mathrm{~b}$ & $74 \mathrm{~b}$ & $7,0 \mathrm{~b}$ & $34,6 \mathrm{~b}$ & $89 \mathrm{a}$ & $90 \mathrm{a}$ \\
T10 & $78 \mathrm{~b}$ & $76 \mathrm{~b}$ & $7,8 \mathrm{a}$ & $32,7 \mathrm{~b}$ & $87 \mathrm{a}$ & $87 \mathrm{a}$ \\
T11 & $79 \mathrm{~b}$ & $77 \mathrm{~b}$ & $7,5 \mathrm{a}$ & $30,0 \mathrm{a}$ & $91 \mathrm{a}$ & $85 \mathrm{a}$ \\
T12 & $85 \mathrm{a}$ & $83 \mathrm{a}$ & $8,3 \mathrm{a}$ & $29,0 \mathrm{a}$ & $87 \mathrm{a}$ & $85 \mathrm{a}$ \\
\hline Teste F & $85,5^{* *}$ & $69,1^{* *}$ & $12,7 * *$ & $6,6^{* *}$ & $61,3^{* *}$ & $12,6^{* *}$ \\
CV $(\%)$ & 4,6 & 7,9 & 14,6 & 10,8 & 10,9 & 12,2 \\
\hline
\end{tabular}

${ }^{(1)}$ Médias seguidas de letras iguais, nas colunas, não diferem entre si, pelo teste de Scott-Knott, a 5\% de probabilidade. ${ }^{(2)}$ T1, arranquio; T2, recolha; $\mathrm{T} 3$, transporte; T4, secagem; T5, armazenamento por dois meses; T6, armazenamento por quatro meses; $\mathrm{T} 7$, armazenamento por seis meses; $\mathrm{T} 8$, trilha mecânica; T9, classificação por tamanho; T10, separação pela mesa densimétrica; T11, seleção por coloração; T12, tratamento químico comercial. **Significativo a $1 \%$ de probabilidade, pelo teste $\mathrm{F}$. beneficiamento a aprimorou (Tabela 4). As etapas de trilha mecânica, classificação, separação por densidade, coloração e o tratamento químico de sementes contribuíram para o sucesso do processo de produção de sementes de elevada qualidade.

Embora o beneficiamento, etapa essencial em qualquer programa de produção de sementes, aprimore as boas características do lote (Ferreira \& Sá, 2010), não melhora a qualidade fisiológica e sanitária dos lotes de sementes de amendoim, conforme verificado por Fessel \& Barreto (2000) e Santos et al. (2013b). Com o manuseio das sementes durante o beneficiamento, espera-se que as sementes apresentem danos, o que ocasiona redução da germinação e do desempenho em campo (Butts et al., 2007). Portanto, por meio de estudos, medidas corretivas devem ser realizadas para o aumento da eficiência do beneficiamento de sementes de amendoim.

No primeiro ano agrícola, os caminhões carregados com sementes aguardavam no pátio da UBS por até seis dias, até a descarga, sujeitando-se a intempéries. Essa prática era comumente observada em outros anos agrícolas. Após a identificação de problemas durante o beneficiamento, no ano agrícola de 2011/2012 foram tomadas medidas corretivas na recepção das sementes e nas regulagens das máquinas de beneficiamento. Dessa forma, os caminhões carregados com sementes, ao chegar na UBS, foram direcionados à amostragem do teor de umidade e, em seguida, às moegas de recebimento. Para melhorar a eficiência do processo na etapa de trilha mecânica, os equipamentos foram substituídos. Assim, houve melhoria acentuada na germinação e desempenho em campo das sementes provenientes do ano 2012/2013, logo após as mudanças no processo de produção das sementes.

Em outras espécies cultivadas, o beneficiamento apresenta inúmeras vantagens. Em sementes de arroz, Pereira et al. (2012) observaram aumento gradativo da qualidade física do lote, após a passagem em cada máquina, ao longo do beneficiamento. Em sementes de milho, Ferreira \& Sá (2010) observaram melhoria da qualidade das sementes com o beneficiamento.

O desempenho de sementes de amendoim depende de sua qualidade inicial, do teor de água no armazenamento (Diniz et al., 2012) e do tratamento que a semente recebe durante toda a linha do beneficiamento (Santos et al., 2013b). Redução do vigor de sementes de amendoim da 'Runner IAC 886 ' foi verificada após 
seis meses de armazenamento $\left(20^{\circ} \mathrm{C}\right.$ e $\left.50 \% \mathrm{UR}_{\mathrm{ar}}\right)$, o que ocasionou o descarte dos lotes (Diniz et al., 2012).

Após o ponto de maturidade fisiológica, em que a semente apresenta o máximo potencial de germinação e vigor e máximo acúmulo de massa de matéria seca, o processo de deterioração ocorre naturalmente. Juntamente com o processo de deterioração, após a maturidade fisiológica, também pode ocorrer redução da qualidade fisiológica, como observado no presente trabalho, em consequência do manuseio durante a colheita, do transporte e do beneficiamento das sementes na UBS. Assim, o tratamento da semente durante estas etapas pode comprometer todo o lote, caso não seja efetuado de forma adequada a assegurar o potencial de desempenho, quando atingida a maturidade fisiológica.

\section{Conclusões}

1. O armazenamento promove a contaminação de $100 \%$ das sementes de amendoim por Aspergillus spp.

2. O tratamento químico é eficiente na recuperação da qualidade sanitária das sementes de amendoim.

3. As etapas de trilha mecânica e armazenamento reduzem a qualidade fisiológica das sementes de amendoim.

\section{Agradecimentos}

À Fundação de Amparo à Pesquisa do Estado de São Paulo (Fapesp), ao Conselho Nacional de Desenvolvimento Científico e Tecnológico (CNPq) e à Cooperativa dos Plantadores de Cana da Zona de Guariba (Coplana).

\section{Referências}

ATAYDE, D.D.; REIS, T.A.; GODOY, I.J.; ZORZETE, P.; REIS, G.M.; CORREA, B. Mycobiota and aflatoxins in a peanut variety grown in different regions in the state of São Paulo, Brazil. Crop Protection, v.33, p.7-12, 2012. DOI: 10.1016/j.cropro.2011.11.013.

BALOTA, M.; PHIPPS, P. Comparison of Virginia and Runner-type peanut cultivars for development, disease, yield potential, and grade factors in eastern Virginia. Peanut Science, v.40, p.15-23, 2013. DOI: 10.3146/PS12-4.1.

BARBOSA, R.M.; SANTOS, J.F. dos; LOPES, M. de M.; PANIZZI, R. de C.; VIEIRA, R.D. Chemical control of pathogens and the physiological performance of peanut seeds. Journal of Food, Agriculture and Environment, v.11, p.322-326, 2013.

BARBOSA, R.M.; SILVA, C.B. da; MEDEIROS, M.A. de; CENTURION, M.A.P.C. da; VIEIRA, R.D. Condutividade elétrica em função do teor de água inicial de sementes de amendoim. Ciência Rural, v.42, p.45-51, 2012. DOI: 10.1590/ S0103-84782012000100008.

BITTENCOURT, S.R.M. de; MENTEN, J.O.M.; ARAKI, C.A. dos S.; MORAES, M.H.D. de; RUGAI, A. da D.; DIEGUEZ, M.J.; VIEIRA, R.D. Eficiência do fungicida carboxin + thiram no tratamento de sementes de amendoim. Revista Brasileira de Sementes, v.29, p.214-222, 2007. DOI: 10.1590/ S0101-31222007000200028.

BRANCH, W.D.; BOSTICK, J.P.; WILLIAMS, E.J.; BEASLEY-JUNIOR, J.P. Determination of the relative maturity range for the 'Georgia-02C' peanut cultivar. Peanut Science, v.37, p.106-109, 2010. DOI: 10.3146/PS09-023.1.

BUTTS, C.L.; FAIRCLOTH, W.H.; LAMB, M.C.; NUTI, R.C.; ROWLAND, D.L.; SORENSEN, R.B.; GUERKE W.R. Effect of bulk handling on runner peanut seed quality. Peanut Science, v.34, p.22-26, 2007. DOI: 10.3146/0095-3679(2007)34[22:EOBHOR]2 $.0 . \mathrm{CO} ; 2$.

CARLEY, D.S.; JORDAN, D.L.; DHARMASRI, L.C.; SUTTON, T.B.; BRANDENBURG, R.L.; BURTON, M.G. Peanut response to planting date and potential of canopy reflectance as an indicator of pod maturation. Agronomy Journal, v.100, p.376-380, 2008. DOI: 10.2134/agrojnl2006.0352.

CARVALHO, N.M. de; NAKAGAWA, J. (Ed.). Sementes: ciência, tecnologia e produção. 5.ed. Jaboticabal: Funep, 2012. 590p.

DINIZ, R.S.; SÁ, M.E. de; ABRANTES, F.L.; SOUZA, L.C.D. de; DAIUTO, E.R. Qualidade de sementes em função do tempo de armazenamento em amendoim. Revista Iberoamericana de Tecnología Postcosecha, v.13, p.86-91, 2012.

DORNER, J.W. Relationship between kernel moisture content and water activity in different maturity stages of peanut. Peanut Science, v.35, p.77-80, 2008. DOI: 10.3146/PS07-101.1.

FERREIRA, R.L.; SÁ, M.E. de. Contribuição de etapas do beneficiamento na qualidade fisiológica de sementes de dois híbridos de milho. Revista Brasileira de Sementes, v.32, p.99-110, 2010. DOI: 10.1590/S0101-31222010000400011.

FESSEL, S.A.; BARRETO, M. Avaliação da qualidade fisiológica e sanitária de sementes de amendoim durante o beneficiamento. Revista Brasileira de Sementes, v.22, p.126-130, 2000.

GADOTTI, G.I.; VILLELA, F.A.; BAUDET, L. Influência da mesa densimétrica na qualidade de sementes de cultivares de tabaco. Revista Brasileira de Sementes, v.33, p.372-378, 2011. DOI: $10.1590 / \mathrm{S} 0101-31222011000200020$.

HARO, R.J.; DARDANELLI, J.L.; OTEGUI, M.E.; COLLINO, D.J. Seed yield determination of peanut crops under water deficit: Soil strength effects on pod set, the source-sink ratio and radiation use efficiency. Field Crops Research, v.109, p.24-33, 2008. DOI: 10.1016/j.fcr.2008.06.006.

LEONEL, C.L.; FREDDI, O. da S.; BEUTLER, A.N.; CENTURION, M.A.P. da C.; CENTURION, J.F. Influência da compactação do solo no crescimento radicular e na produtividade do amendoim. Científica, v.35, p.51-60, 2007. 
LIMONARD, T. A modified blotter test for seed health. Netherland Journal of Plant Pathology, v.72, p.319-321, 1966. DOI: 10.1007/ BF02650226.

LOPES, M. de M.; PRADO, M.O.D.; SADER, R.; BARBOSA, R.M. Efeitos dos danos mecânicos e fisiológicos na colheita e beneficiamento de sementes de soja. Bioscience Journal, v.27, p.230-238, 2011.

MAGUIRE, J.D. Speed of germination: aid in selection and evaluation for seedling emergence and vigor. Crop Science, v.2, p.176-177, 1962. DOI: 10.2135/cropsci1962.0011183X00020002 $0033 x$.

MARCHI, J.L. de; CICERO, S.M.; GOMES JUNIOR, F.G. Utilização da análise computadorizada de plântulas na avaliação do potencial fisiológico de sementes de amendoim tratadas com fungicida e inseticida. Revista Brasileira de Sementes, v.33, p.652-662, 2011. DOI: 10.1590/S0101-31222011000400007.

MARCOS-FILHO, J.; VIEIRA, R.D. Seed vigor tests: procedures - conductivity tests. In: BAALBAKI, R.Z.; ELIAS, S.G.; MARCOS-FILHO, J.; MCDONALD, M.B. (Ed.). Seed vigor tests handbook. Ithaca: Association of Official Seed Analysts, 2009. p.186-200.

MORTON, B.R.; TILLMAN, B.L.; GORBET, D.W.; BOOTE, K.J. Impact of seed storage environment on field emergence of peanut (Arachis hypogaea L.) cultivars. Peanut Science, v.35, p.108-115, 2008. DOI: 10.3146/PS07-111.1.

NAUTIYAL, P.C. Seed and seedling vigour traits in groundnut (Arachis hypogaea L.). Seed Science and Technology, v.37, p.721-737, 2009. DOI: 10.15258/sst.2009.37.3.19.

PEREIRA, C.E.; ALBULQUERQUE, K.S.; OLIVEIRA, J.A. Qualidade física e fisiológica de sementes de arroz ao longo da linha de beneficiamento. Semina: Ciências Agrárias, v.33, p.2995-3002, 2012.

PIMENTEL-GOMES, F.P. Curso de estatística experimental. 15.ed. Piracicaba: FEALQ, 2009. 451p.
REGRAS para análise de sementes. Brasília: MAPA/DAS/ACS, 2009. 395p.

SADER, R.; CHALITA, C.; TEIXEIRA, L.G. Influência do tamanho e do beneficiamento na injúria mecânica de sementes de amendoim. Revista Brasileira de Sementes, v.13, p.45-51, 1991.

SANTOS, E.P. dos; SILVA, R.P. da; BERTONHA, R.S.; NORONHA, R.H.F.; ZERBATO, C. Produtividade e perdas de amendoim em cinco diferentes datas de arranquio. Revista Ciência Agronômica, v.44, p.695-702, 2013a. DOI: 10.1590/ S1806-66902013000400005.

SANTOS, F. dos; MEDINA, P.F.; LOURENÇÃO, A.L.; PARISI, J.J.D.; GODOY, I.J. de. Qualidade de sementes de amendoim armazenadas no Estado de São Paulo. Bragantia, v.72, p.310-317, 2013b. DOI: 10.1590/brag.2013.029.

SANTOS, J.F.; SANCHES, M.F.G.; BARBOSA, R.M.; LEÃO, E.F.; VIEIRA, R.D. Optimising tetrazolium test procedures to evaluate the physiological potential of peanut seeds. Seed Science and Technology, v.40, p.215-228, 2012. DOI: 10.15258/ sst.2012.40.2.07.

SILVEIRA, P.S. da; PEIXOTO, C.P.; LEDO, C.A. da S.; PASSOS, A.R.; BORGES, V.P.; BLOISI, L.F.M. Fenologia e produtividade do amendoim em diferentes épocas de semeadura no Recôncavo Sul Baiano. Bioscience Journal, v.29, p.553-561, 2013.

VECHIATO, M.H.; KOHARA, E.Y.; MENTEN, J.O.M. Efeito do armazenamento em sementes de feijão tratadas com fungicidas. Fitopatologia Brasileira, v.19, p.204-208, 1994.

VIEIRA, R.D.; PENARIOL, A.L.; PERECIN, D.; PANOBIANCO, M. Condutividade elétrica e teor de água inicial das sementes de soja. Pesquisa Agropecuária Brasileira, v.37, p.1333-1338, 2002. DOI: 10.1590/S0100-204X2002000900018.

WANG, M.L.; RAYMER, P.; CHINNAN, M.; PITTMAN, R.N. Screening of the USDA peanut germplasm for oil content and fatty acid composition. Biomass and Bioenergy, v.39, p.336-343, 2012. DOI: 10.1016/j.biombioe.2012.01.025.

Recebido em 19 de março de 2014 e aprovado em 21 de novembro de 2014 